\title{
Inovações tecnológicas e hibridismos no álbum-aplicativo Biophilia, de Björk
}

\author{
Technological innovations and hybridity in the album-application \\ Biophilia, by Björk
}

\section{Innovaciones tecnológicas e híbridas en el álbum-aplicación Biophilia, de Björk}

\author{
Rodrigo Trasferetti ${ }^{l}$ \\ Roberto Elísio dos Santos ${ }^{2}$
}

\begin{abstract}
Resumo
Nos estudos da comunicação, a transição midiática ocorrida na indústria fonográfica nos últimos anos passou por grandes alterações nos formatos de suportes e nos nichos de negócios, por meio da evolução da tecnologia com o avanço da era digital. Diante desse fato, este trabalho analisou o primeiro álbum-aplicativo desenvolvido no mundo, o app Biophilia (2011), da artista islandesa Björk, que marca essa transição. A pesquisa realizada, qualitativa e de nível exploratório, usou a técnica da análise documental. $\mathrm{O}$ resultado evidencia os modos de parcerias entre profissionais que produzem inovação e atuam como visionários da cultura pop, fomentando um novo cenário na história da indústria cultural, além de relacionar o álbum-aplicativo como um produto hipermidiático ligado às novas mídias e à cibercultura.
\end{abstract}

\begin{tabular}{|c|c|}
\hline & Acesse este artigo online \\
\hline \multirow{2}{*}{ 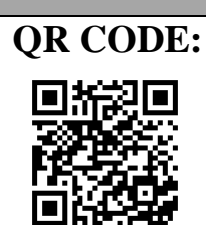 } & $\begin{array}{l}\text { Website: } \\
\text { http://www.revistas.ufg.br/index.php/ci }\end{array}$ \\
\hline & $\begin{array}{l}\text { DOI: } \\
\text { http://dx.doi.org/10.5216/ci.v20i2.46259 }\end{array}$ \\
\hline
\end{tabular}

Palavras-chave: Comunicação midiática. Biophilia Björk. Álbum-aplicativo.

\section{Abstract \\ In communication studies, the media transition in the music industry in recent years has undergone major changes in} media formats and business niches, through the evolution of technology with the advancement of the digital age. Considering this factor, the research selected the first application-album developed in the world, the app Biophilia (2011) of the Icelandic artist Björk that marks this transition. This research, qualitative and of exploratory level, used the technique of documentary analysis. The result collaborates, in the clarifying and understanding, with the modes of partnerships between professionals who produce innovation and act as visionaries of pop culture, fostering a new scenario in the history of the cultural industry, and relates the application-album as a hypermedia product linked to the new media categories and of cyber culture.

Keywords: Media communication. Biophilia Björk. Album-application.

\section{Resumen}

En los estudios de comunicación, la transición de medios de comunicación en la industria de la música en los últimos años pasó por grandes cambios en los formatos de medios y nichos de negocio, a través de la evolución de la tecnología para el avance de la era digital. Teniendo en cuenta este factor, este

\footnotetext{
1 Mestre em Comunicação pela Universidade Municipal de São Caetano do Sul (USCS). E-mail: r.trasferetti@gmail.com

${ }^{2}$ Livre docente em Comunicação pela ECA-USP e professor do Programa de Mestrado em Comunicação da Universidade Municipal de São Caetano do Sul (USCS). E-mail: roberto.elisio@uscs.edu.br
}

Comun. \& Inf., Goiânia, GO, v. 20, n. 2, p. 113-131, jul./jun. 2017 
estudio analizó el primer álbum de aplicación desarrollada en el mundo, lo app Biophilia (2011) del artista islandesa Björk, que marca la transición. La investigación, del nivel cualitativo y exploratorio, se utilizó la técnica de análisis documental. El resultado muestra las formas de asociaciones entre los profesionales que producen la innovación y actúan como visionarios de la cultura pop, el fomento de un nuevo escenario en la historia de la industria cultural, además de relacionar la aplicación-álbum como un producto hipermedia conectado a nuevos medios de comunicación y el ciberespacio.

Palabras clave: Medios de comunicación. Biophilia Björk. Álbum-aplicación.

\section{INTRODUÇÃO}

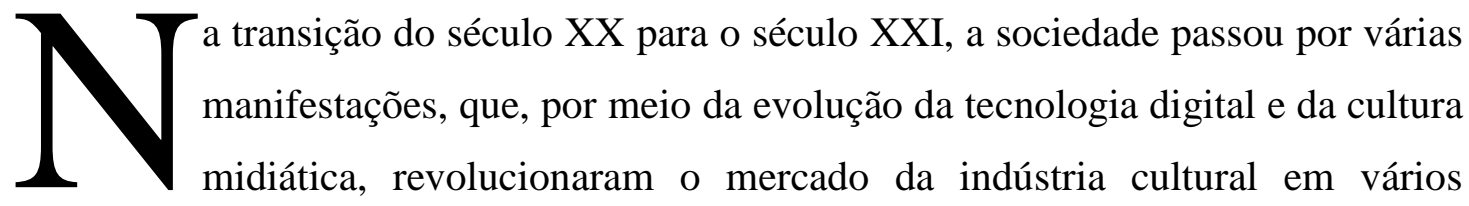
setores e segmentos. Mudanças significativas ocorreram na indústria musical por intermédio de hibridismos, mesclas, união e sincretismos de linguagens. O desenvolvimento da era digital trouxe um avanço considerável à indústria fonográfica, que passou a ter mudanças em seu formato de produção, no suporte midiático e nos nichos de negócios através da cultura criativa. As inovações comunicacionais e tecnológicas proporcionaram interações entre os atores do mercado, fomentando diferentes plataformas aos produtores de conteúdo. Nesse cenário, novos elos artísticos ocorreram graças à união de linguagens, e as inovações trazem uma grande mudança na indústria cultural, ao gerar, por meio da cibercultura, alterações na fronteira entre artista, produto, obra e público.

Na música, a união híbrida transcultural e tecnocomunicacional é alvo das atenções que têm como desafio instigar as infinitas formas de mesclas e uniões na produção da obra de arte por meio de experimentalismos de linguagens que culminou na transição midiática da indústria fonográfica, com o advento do álbum-aplicativo, objeto-produto-midiático inovador, pós-moderno e hipermidiático de integração de linguagens comunicacionais e semióticas por meio do uso da tecnologia digital na contemporaneidade.

Diante disso, esta pesquisa teve como objetivo analisar e identificar as inovações na linguagem musical, observadas nas mesclas híbridas, midiáticas e tecnológicas do álbumaplicativo Biophilia (2011), da artista islandesa Björk, por seu ineditismo, experimentalismo e criatividade, marcando a transição de suporte midiático na indústria da cultura e do entretenimento, sendo o primeiro a ser desenvolvido na história da indústria musical no mundo. Pretende-se ainda contribuir com as áreas da comunicação social, científica, acadêmica e cultural por meio de reflexões sobre a produção cultural com foco na música,

Comun. \& Inf., Goiânia, GO, v. 20, n. 2, p. 113-131, jul./jun. 2017 
uma das áreas dos estudos das mídias na comunicação, e também para a ciência das artes, ao relacionar e organizar informações para o avanço do estudo científico da área, sem esgotar os temas.

\section{MATERIAL E MÉTODO}

O trabalho é uma pesquisa qualitativa de nível exploratório e, como metodologia, adota a análise documental que "compreende a identificação, a verificação e a apreciação de documentos para determinado fim. No caso da pesquisa científica, é, ao mesmo tempo, método e técnica" (DUARTE; BARROS, 2015, p. 271-272). Segundo os autores, suas fontes são frequentemente de origem secundária como "a mídia impressa (gravações magnéticas de som e vídeo, gravações digitais de áudio e imagem) e relatórios técnicos" (DUARTE; BARROS, 2015, p. 272).

A análise documental, muito mais que localizar, identificar, organizar e avaliar textos, som e imagem, funciona como expediente eficaz para contextualizar fatos, situações, momentos. Consegue dessa maneira introduzir novas perspectivas em outros ambientes, sem deixar de respeitar a substância original dos documentos (DUARTE; BARROS, 2015, p. 276).

Buscamos definições e reflexões sobre o processo de hibridismos, segundo o conceito de Burke (2003) e Canclini (2013), com a união de linguagens ao contextualizar aspectos da indústria musical com foco nos modos de comunicação, atrelado às teorias contemporâneas sob o contexto da cultura criativa, que, por meio da tecnologia digital, inova a indústria fonográfica como parte do processo de hibridização entre linguagens artísticas, estéticas e midiáticas.

Esse tipo de inovação comunicacional na indústria cultural se enquadra como uma inovação radical e "tem como característica o desenvolvimento e introdução de um novo produto, processo ou forma de organização da produção inteiramente nova" (VARGAS; GOULART, 2008, p. 167). Além disso, tem crescido substancialmente ao longo dos anos e se consolida como uma inovação mercadológica na música, na indústria cultural e do entretenimento como incentivo ao consumo de um produto inovador e alternativo aos praticados no mercado.

A evolução da comunicação na música, por meio da tecnologia na era digital, passa a concretizar um papel importante quanto à sua diversidade cultural em seus modos de 
expressão artística e participativa, tendo em vista que "a comunicação assumiu seu lugar e anuncia-se como parâmetro por excelência da evolução da humanidade" (MATTELART; MATTELART, 2012, p. 189), além de possibilitar dinâmicas, experimentações de linguagens e experiências estéticas com relações múltiplas, híbridas e midiáticas na cibercultura contemporânea por meio das características das novas mídias digitais (MANOVICH, 2001).

O conceito de gamificação por meio da utilização dos dispositivos móveis e dos variados aplicativos com seus inúmeros recursos e funcionalidades é importante para a compreensão das inovações comunicacionais provindas da união de linguagens e seus usos criativos, além dos efeitos diversos da tecnologia digital. $\mathrm{O}$ objetivo, ao trazer o conceito de gamificação, é colaborar para discussões e para o aprofundamento do uso da tecnologia interativa e inteligente na indústria fonográfica, pois as tecnologias digitais, os dispositivos móveis e os "álbuns-aplicativos" podem colaborar significativamente com a evolução da indústria musical no século XXI.

A gamificação se foca no envolvimento do usuário com o aplicativo por meio de um jogo que pode recompensá-lo se ele se engajar cada vez mais com os recursos disponíveis. Segundo os autores Shankari et al. (2015, p. 5-6), na gamificação são inclusos: 1) Clareza de objetivos e regras (exibidos na tela do display); 2) Sistema de feedback frequente (em que o usuário avança nos estágios do jogo); 3) Desafios gerenciáveis (acúmulo de pontos no sistema); 4) Tornar as etapas mais difíceis (desafia o usuário, por escala logarítmica, a avançar de nível); 5) Aumento de novidades (mudanças a cada nova etapa) e; 6) Envolvimento voluntário (a qualquer momento o usuário pode instalar, jogar, interagir ou desinstalar o aplicativo). Para os autores, “[...] a diferença entre a visualização de dados e o jogo é vista na imposição de um julgamento de valor sobre o padrão ${ }^{3 "}$ (SHANKARI et al., 2015, p. 6), em que o usuário tem a opção de escolher e alterar seu modo de navegação e interação com o jogo à vontade, o que lhe permite descobrir aquilo que mais o agrada e motiva. "Mas essa escolha aumenta sua carga cognitiva. Portanto, a escolha na tela pode afetar o engajamento em qualquer direção" (SHANKARI et al., 2015, p. 6).

A gamificação se tornou um grande mote para uma nova economia na indústria fonográfica. Os autores Lemes; Tomaselli e Camarotti (2012) avaliam a economia digital e o mercado de jogos em sua contínua conectividade e interatividade por meio dos dispositivos

\footnotetext{
${ }^{3}$ Tradução do autor: "The difference between the data view and the game view is the imposition of a value judgment on travel patterns".

${ }^{4}$ Tradução do autor: "But this choice increases their cognitive load. Therefore the choice screen can affect engagement in either direction".
}

Comun. \& Inf., Goiânia, GO, v. 20, n. 2, p. 113-131, jul./jun. 2017 
móveis, que avançam na indústria fomentando novos modelos de negócios e mudam a forma com que empresas, clientes e fornecedores vêm trabalhando, assim como os produtos e seus modelos na nova fase da economia mundial.

\section{ANÁLISE DO ÁLBUM-APLICATIVO BIOPHILIA, DE BJÖRK}

Biophilia (2011), da cantora islandesa Björk, é o primeiro álbum-aplicativo a ser desenvolvido no mundo. Criado em parceria com a gravadora One Little Indian Records ${ }^{5}$ e a empresa Apple, traz algumas características particulares de inovações híbridas, midiáticas e tecnológicas. Seus criadores divulgam algumas delas, principalmente as características quanto à sua descrição e à informação aos usuários sobre o produto. Está disponível para download no iTunes ${ }^{6}$ para iPhone e iPad, e no Google Play ${ }^{7}$ para smartphone.

Além dos aspectos informados por seus desenvolvedores, como a inspiração da interatividade que veio por meio das "relações entre estruturas musicais e fenômenos naturais, do atômico ao cósmico" (OMINE; HANNS, 2013, p. 2), é preciso mencionar os aspectos híbridos que unem linguagens e experimentalismos contemporâneos por meio da utilização e reprodução da arte aliada às ferramentas tecnológicas digitais e à pós-modernidade, que "no campo da música caracteriza-se pelo caráter da comercialidade na qual ela é produzida" (GARCIA; KESSLER, 2013, p. 4).

A evolução da tecnologia digital proporcionou a criação de suportes midiáticos inovadores que chegam à indústria da cultura e do entretenimento e se consolidam como uma nova ferramenta de comercialização da música em âmbito massivo. Também colaborou para a conexão em rede entre públicos e artistas, bem como com a crise do suporte, ao trazer inovação e uma nova ferramenta de comercialização para alavancar negócios, além de ser uma fonte de difícil pirataria por seu alto grau de tecnologia.

No entanto, sabe-se que "a utilização de novas formas de computadores, como smartphones e tablets, em trabalhos de arte e design interativos e multimídia" (OMINE; HANNS, 2013, p. 9) fomenta inovações na indústria e não se pretende esgotar o tema, mas

\footnotetext{
${ }^{5}$ Disponível em: 〈http://indian.co.uk/>. Acesso em: 20 março 2017.

${ }^{6}$ Disponível em: 〈https://itunes.apple.com/br/app/bjork-biophilia/id434122935?mt=8>. Acesso em: 20 março 2017.

7 Disponível em: <https://play.google.com/store/apps/details?id=com.bjork.biophilia〉. Acesso em: 20 março 2017.
}

Comun. \& Inf., Goiânia, GO, v. 20, n. 2, p. 113-131, jul./jun. 2017 
sim explorar aspectos que possam colaborar com as pesquisas no âmbito dos estudos em comunicação, arte, música, cultura, design e tecnologia.

Björk, ao longo de sua carreira, se consolidou como uma artista experimental e alternativa e sempre se destacou por inovar e mesclar linguagens em suas experiências artísticas, assim como em seus produtos.

Biophilia também conta com outros produtos desenvolvidos para fãs e colecionadores. Na loja oficial da cantora, além de se encontrar à venda os trabalhos anteriores, é possível adquirir: a versão das músicas remixadas de Biophilia nos formatos disco de vinil, CD ou digital; o álbum em disco de vinil; um livro com três modelos de cores diferentes que contam a concepção de Biophilia e bastidores do show ao vivo; camisetas com letras das músicas e o logotipo do projeto musical estampado e, na época antes do lançamento, era possível adquirir a versão de colecionador de Biophilia, uma caixa de madeira de carvalho contendo 10 diapasões coloridos, cada um representando uma das músicas, além do encarte e do CD (GARCIA; KESSLER, 2013, p. 10).

Destaca-se em sua expressiva produção o fato de compartilhar conteúdos e materiais com outros artistas, o que colabora para a mistura de identidades, hibridismos culturais e experimentalismos ao unir linguagens, por exemplo, quando DJs se utilizam de sua obra para realizar remixagens. Biophilia é um álbum que foi remixado, assim como outros de seu repertório, e pode ser acessado por meio da plataforma SoundCloud ${ }^{8}$ via streaming, na qual estão disponíveis diversas remixagens por diferentes artistas e produtores. Este trabalho, porém, foca a análise no álbum-aplicativo.

Biophilia explora de modo inovador a união de ferramentas e tecnologias por meio de hibridismos que mesclam arte, música, multimídia, tecnologia, design e linguagens relacionadas à natureza e à semiótica. Ao utilizar o app, o ouvinte/visualizador embarca em uma viagem no universo. Em cada navegação há um processo em que o usuário tem experiências individuais e particulares ao som das canções, trechos de samples e efeitos diversos, além de obter múltiplas ferramentas e aplicações interativas.

Björk disponibiliza em seu canal no YouTube ${ }^{9}$ um vasto material de seu repertório, inclusive os tutoriais ${ }^{10}$ do álbum-aplicativo Biophilia ${ }^{11}$, que facilitam a compreensão do usuário sobre o app. Seu design e layout são compostos por uma galáxia tridimensional que se

\footnotetext{
${ }^{8}$ Disponível em: <https://soundcloud.com/search?q=biophilia〉. Acesso em: 20 março 2017.

${ }_{9}^{9}$ Disponível em: <https://www.youtube.com/channel/UCFbRdRGijPR4oBjQ0fVCSmw〉. Acesso em: 20 março 2017.

${ }_{10}$ Disponível em: 〈https://www.youtube.com/results?search query=biophilia+app+tutorial〉. Acesso em: 20 março 2017.

${ }^{11}$ Disponível em: <https://www.youtube.com/watch?v=dikvJM_zA4>. Acesso em: 20 março 2017.
}

Comun. \& Inf., Goiânia, GO, v. 20, n. 2, p. 113-131, jul./jun. 2017 
movimenta em conjunto com o modo de manipulação do dispositivo móvel pelo usuário. Sua bússola permite a navegação entre o universo 3D e a lista de canções bidimensional. Cada uma das dez canções representa uma constelação, trazendo fenômenos relacionados com a natureza e aplicações diferenciadas. As canções autorais e originais se mesclam por meio do design do app com a arte, música, tecnologia, interatividade e entretenimento. O usuário, ao consumir o produto midiático inovador com os artefatos musicais disponíveis, tem inclusive acesso fácil à educação musical por meio do uso da tecnologia e do entretenimento proporcionados pelas ferramentas e aplicações do seu design arrojado.

Figura 1 - Menu principal. Galáxia 3D em órbita com acesso às constelações-canções

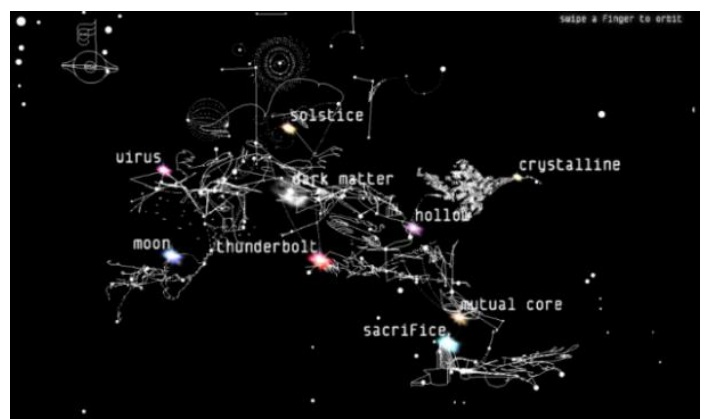

Fonte: Álbum-aplicativo Biophilia (2011)

Ao tocar nas estrelas, que são as canções, o usuário é redirecionado a uma constelação, em que poderá ter experiências diversas que combinam a interface 3D da galáxia com arte, música, jogo, interatividade, criatividade, tecnologia, animação, notação musical, karaokê, entretenimento, produção musical etc. Trata-se de artefatos que unem a produção alternativa às convencionais do mercado e representam um modo inovador de se produzir e consumir música em um ambiente completamente tecnológico e midiatizado, de aprendizado e entretenimento, ao explorar recursos multimídia com as tecnologias móveis e interativas da contemporaneidade.

Ao navegar na galáxia Biophilia por meio de seu menu principal, que em órbita se movimenta instantaneamente enquanto se utiliza o dispositivo móvel por meio de sua bússola, abre-se a possibilidade de escolher a constelação-canção com a qual se quer interagir, ao som de efeitos espaciais. Estão disponíveis dentro do álbum-aplicativo todas as canções do álbum Biophilia, contendo experiências interativas que mexem com a criatividade do usuário. As canções são: Cosmogony, Crystalline, Dark Matter, Hollow, Moon, Mutual Core, Sacrifice, Solstice, Thunderbolt e Virus. 
No menu principal, em órbita no espaço, ao tocar na constelação-canção escolhida, o usuário passa por uma experiência de viagem espacial. Em seguida, tem acesso ao menu individual da canção desejada e algumas opções de navegação nos seguintes botões: Play, Animation, Lyrics, Score e Credits. O layout dos menus individuais das constelações-canções é diferente, mudando sua coloração, as ferramentas, os jogos e aplicações. Porém, é padronizado quanto aos botões e às opções de menus.

O álbum-aplicativo Biophilia, lançado em 2011, é uma criação multimídia que explora o universo de forma ampla, seja musical, tecnológica, educacional ou comunicacional. O produto pode ser apreciado sem maiores intenções, mas também pode proporcionar uma experimentação semiótica por meio da utilização de linguagens diferentes, forças físicas da natureza cósmica, processos de composição, estruturas musicais, interatividade midiática, dos quais a música faz parte e colabora, inclusive para a educação e produção musical.

A inovação desenvolvida na indústria musical através desse novo produto midiático traz à tona a união de diferentes tipos de profissionais, como artistas, compositores, produtores, diretores, designers, cientistas, fabricantes de instrumentos e tecnologias, desenvolvedores e engenheiros de softwares, programadores de computação gráfica e audiovisual e de tecnologia da informação etc. O álbum-aplicativo foi desenvolvido pela artista Björk e seus colaboradores, desenvolvedores de aplicativos interativos e engenheiros de softwares, coordenado pelo empresário e artista multimídia Scott Snibbe, além dos diversos profissionais citados nos créditos do app $^{12}$.

A união desses profissionais resultou na produção de um grande caleidoscópio musical, em um projeto hipermultimídia amplo, disponibilizado em dispositivos móveis, com novos protocolos de interatividade, consumo e produção musical. Em cada canção há ferramentas, características e aplicações diferenciadas em seus jogos interativos que dão a possibilidade do usuário ser um coautor da obra, como será visto a seguir em alguns dos exemplos analisados.

12 Damian Taylor, Dave Addey, Deeje Cooley, Drew Berry, Graham Mcdermott, Henrique Schatter Manfroi/Sulistas, Henry Cooke, James Merry, John Cromie, John Simon Jr., Kodama Studios, Lisa Ching, Luc Barthelet, M/M Paris, Margret Vilhjalmsdottir, Mark Danks, Mark Danks, Max Weisel, Max Whitby, Nathan Heigert, Sarah Flannery, Stephen Malinowski, Theo Gray, Theodore Gray e Touch Press.

Comun. \& Inf., Goiânia, GO, v. 20, n. 2, p. 113-131, jul./jun. 2017 
Figura 2 - Menu individual da canção Cosmogony

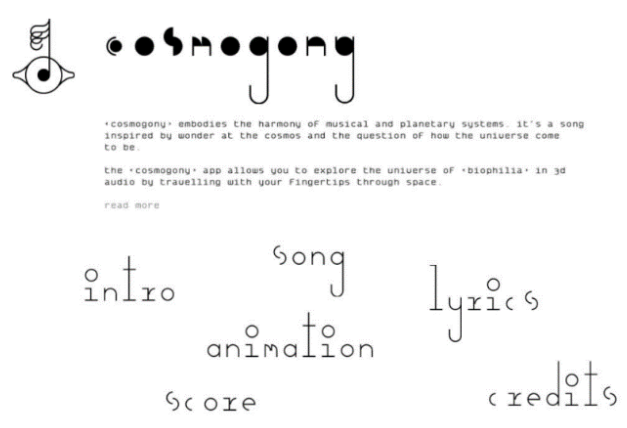

Fonte: Álbum-aplicativo Biophilia (2011)

Ao iniciar a navegação em Cosmogony, o usuário tem acesso à introdução do álbumaplicativo. Ao clicar em Intro, é apresentado o vídeo de introdução, narrado por David Attenborough, que leva o usuário a uma viagem na galáxia de possibilidades de Biophilia e que irá encontrar no app. Esse vídeo de introdução do app está disponível na página oficial de Björk $^{13}$, no YouTube.

Ao entrar em Song (única canção a ter essa opção), inicia-se a navegação na galáxia de Biophilia, com a reprodução da canção Cosmogony. A animação passa por todas as canções presentes no álbum-aplicativo, que são simbolizadas por suas constelações. Ao finalizar a animação, o usuário tem acesso às outras opções, como: Animation, que reproduz a canção com animações abstratas e com a legenda da letra da canção, que é reproduzida simultaneamente enquanto ocorre sua reprodução; Lyrics, em que é disponibilizada a letra original da canção; Score, que disponibiliza a partitura da canção reproduzida sem a voz, o que possibilita ao usuário utilizá-la como karaokê; e Credits, em que são informados os créditos dos desenvolvedores do aplicativo e da interatividade midiática da canção. Em cada canção há um jogo com linguagens, características, ferramentas, funcionalidades, usos e aplicações que se diferenciam.

${ }^{13}$ Disponível em: <https://www.youtube.com/watch?v=o8AELvVUFLw>. Acesso em: 20 mar. 2017.

Comun. \& Inf., Goiânia, GO, v. 20, n. 2, p. 113-131, jul./jun. 2017 
Figura 3 - Menu individual da canção Moon

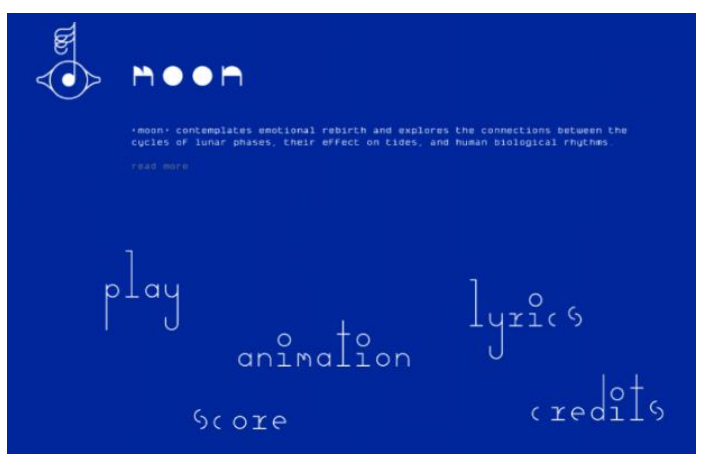

Fonte: Álbum-aplicativo Biophilia (2011)

No menu da canção Moon (assim como em todas as canções do app), ao selecionar a opção Play, o usuário tem acesso a um jogo interativo enquanto samples da canção são reproduzidos. Por meio de programações, ele pode brincar e interagir com algumas ferramentas que variam de canção para canção, mas com isso usa sua criatividade para poder influenciar possíveis alterações na linguagem da canção. Há, ainda, por exemplo, a possibilidade de mexer no timbre sonoro, utilizar samples diferenciados, gravar, salvar e reproduzir sua experiência etc.

O usuário, ao utilizar as várias ferramentas possíveis, passa a ter condições de interagir com o produto midiático (característica presente em todo o álbum-aplicativo) e, ao mesmo tempo, criar suas composições por meio das ferramentas e aplicações disponíveis no app. Com isso, passa a ser também um cocriador da obra em conjunto com a artista, engenheiros, colaboradores e empresas que desenvolveram o produto.

Há inúmeras possibilidades de experiências e utilizações das aplicações. O usuário, inclusive, passa a ser criador de uma obra genuinamente sua, ao utilizar as aplicações por meio da tecnologia disponibilizada por seus criadores e desenvolvedores. Uma de suas características mais marcantes é o fato de que o álbum-aplicativo é um produto inacabado. Ele possui suas programações, mas cada usuário irá utilizá-las da forma que mais lhe satisfizer, diferente do modo de consumo de um CD ou DVD, em que não há a opção de interagir com possibilidades entre linguagens e experimentalismos, mas só de consumir. 
Figura 4 - Jogo interativo da canção Moon

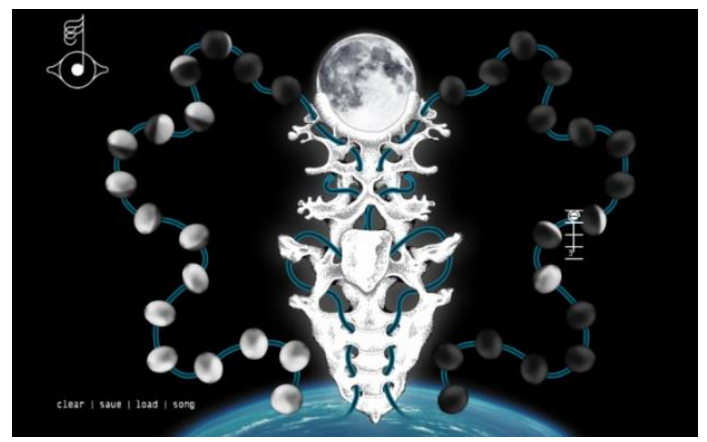

Fonte: Álbum-aplicativo Biophilia (2011)

A canção Moon explora a união emotiva relacionada com as fases da lua por meio de seus ciclos, bem como sua relação e interferência com a maré dos oceanos e com a vida humana. Em suas aplicações, o usuário pode interferir nas condições da reprodução audiovisual e criar sua própria composição. Acima da órbita do planeta Terra, o usuário interage musicalmente com a lua, ao movimentá-la em suas fases minguante, nova, crescente e cheia. Com isso, em cada fase a sonoridade e o andamento da canção são alterados. Ao tocar nas luas menores, ao redor do esqueleto, o usuário faz as mesmas aplicações ao movimentar a lua por suas fases, porém com maiores possibilidades de experimentalismos, pois quanto mais luas estiverem ativadas sonoramente, mais a canção criada pelo usuário terá uma dinâmica diferenciada. Ao tocar no esqueleto, o usuário pode experimentar dinâmicas diversas, diminuir e até parar o andamento. Quanto mais tocar nas possibilidades, mais a corrente musical irá se movimentar.

A linha azul, uma espécie de veia, centraliza e realiza a passagem da corrente musical. É por meio dela que se interligam as luas ao esqueleto central e à Terra, e é por essa veia que é proporcionada a execução musical. "Durante a passagem do fluido azul pelas veias, notas musicais são reproduzidas de acordo com a fase de cada pequena lua. $\mathrm{O}$ usuário pode salvar sua composição e carregá-la posteriormente” (OMINE; HANNS, 2013, p. 4-5). 
Figura 5 - Jogo interativo da canção Thunderbolt

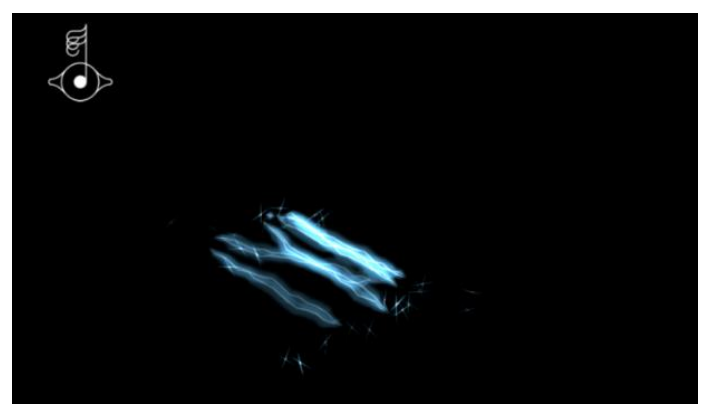

Fonte: Álbum-aplicativo Biophilia (2011)

A canção Thunderbolt traz em seu jogo interativo uma possibilidade de composição e interferência na linguagem da canção original. Por meio de recursos de touch-screen, é possível criar sonoridades que podem se mesclar com a canção, e até mesmo elaborar uma composição única e própria, sem a necessidade de estar mesclada com a canção original. $\mathrm{O}$ usuário utiliza a criatividade ao tocar na tela, o que gera pontos de ligação entre os toques por meio de faíscas elétricas ou raios, os quais reproduzem sonoridades, arpejos e notas enquanto joga de modo aleatório. Uma característica marcante desse jogo é a possibilidade de gerar loops sonoros, que são executados quando o usuário, ao tocar a tela de forma intencional, cria um círculo que liga os pontos elétricos ou raios, e, por meio das faíscas, é reproduzido o som em loop. Enquanto as faíscas estão acesas e ativadas, o loop é reproduzido. Porém, quando perdem sua intensidade, o loop também diminui sua intensidade até sumir.

As faíscas representam, portanto, raios que são criados por meio dos toques do usuário. É possível ainda desenhar com os dedos formas geométricas que reproduzem notas musicais e arpejos sobre a música, enquanto “[...] as posições dos dedos no eixo $\mathrm{X}$ da tela altera as notas tocadas, e as posições no eixo $\mathrm{Y}$ alteram a velocidade dos arpejos" (OMINE; HANNS, 2013, p. 3).

Figura 6 - Jogo interativo da canção Crystalline

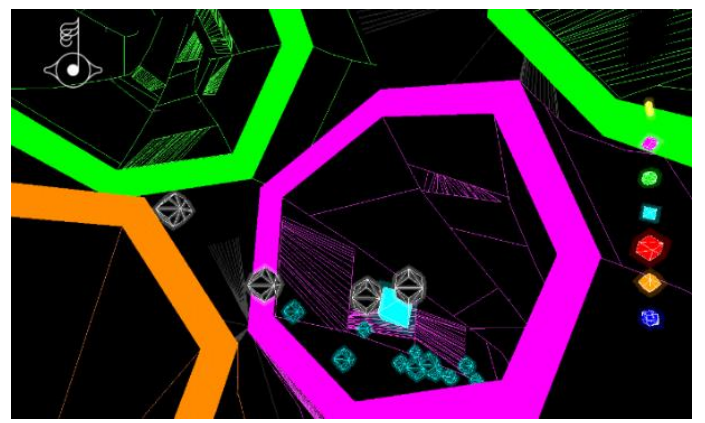

Fonte: Álbum-aplicativo Biophilia (2011)

Comun. \& Inf., Goiânia, GO, v. 20, n. 2, p. 113-131, jul./jun. 2017 
A canção Crystalline traz um jogo interativo que se move por meio da bússola interna do aplicativo. Nele, o usuário utiliza o dispositivo móvel como se fosse um volante e, enquanto se movimenta, a interação surte diferentes efeitos por meio de estruturas de cristais, sob colunas e túneis em uma caverna de cristal. Enquanto o usuário joga, essas formações crescem e, em estado cristalino, se conectam em relações espaciais entre a natureza e a música, ao comparar a representatividade dos estados emocionais da canção com os cristais. A interatividade de Crystalline se assemelha a um videogame, que aguça a criatividade do usuário. Segundo Omine e Hanns (2013):

De todas as peças interativas neste aplicativo, esta é a que mais se assemelha a um videogame convencional. O usuário navega um sistema de túneis em perspectiva tridimensional, e tem como objetivo colecionar cristais encontrados nas paredes desses túneis. Ao colecionar os cristais em sequências exibidas na tela, o usuário descobre novos túneis para serem explorados. Cada túnel corresponde a um trecho específico da música. Dessa forma, o usuário cria seu próprio arranjo da música ao fazer seu caminho por esses túneis. (OMINE; HANNS, 2013, p. 5-6).

Neste jogo, o usuário tem ao lado direito da tela diferentes opções de cristais, que surgem ao longo dos túneis e se unem por meio de suas movimentações. Na medida em que ocorre a interatividade, são apresentadas diferentes opções de túneis: o usuário escolhe para onde quer viajar, por exemplo, para estados internos da terra ou externos do espaço, bem como os cristais que deseja.

Figura 7 - Jogo interativo da canção Dark Matter

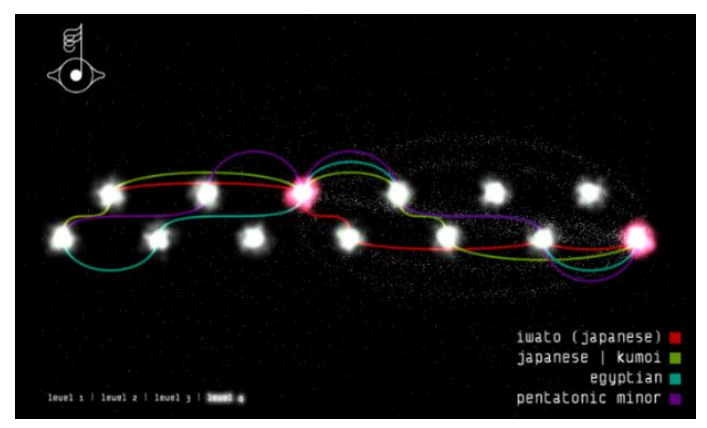

Fonte: Álbum-aplicativo Biophilia (2011)

Em Dark Matter, o usuário tem a possibilidade de conhecer melhor as estruturas musicais e sonoridades de diferentes regiões do mundo, por meio de um jogo interativo que lhe apresenta as harmonias das esferas. Há um mistério que sonda o universo e, nesta canção, 
esse mistério é colocado em questão por meio do cosmos expresso em suas aplicações. O uso da tecnologia aproxima ideias antigas e modernas do espírito criativo dessa música, que representa o invisível que paira o universo. A canção Dark Matter é rodeada de incógnitas. É a única em que o usuário não tem acesso à letra, pelo fato de ela não existir. Porém, traz uma interatividade que conecta a música, com a respiração, com a alma humana e com o cosmos, ou seja, com o sopro da vida.

No jogo interativo, que é dividido em quatro níveis, há uma compreensão sonora e visual das escalas melódica e harmônica, relacionadas com as diferenças sonoras das escalas pentatônicas ocidental e oriental, bem como as diferenças entre tons e semitons, acordes menores e maiores etc. Pode-se utilizar o jogo como um instrumento musical e conhecer, por meio das legendas, os tipos de sonoridades: se ela é pentatônica maior ou menor, se está relacionada com à cultura balinesa, chinesa, mongol, árabe, hindu, japonesa, egípcia etc.

O layout do jogo proporciona ainda uma sensação semiótica. O design faz o usuário embarcar por uma viagem no espaço, seja por seu visual ou por sua sonoridade: "são apresentados 13 pontos luminosos, correspondentes às 12 notas de uma escala musical completa, mais a primeira nota da oitava seguinte" (Omine; Hanns, 2013, p. 5). Além disso, o usuário tem a possibilidade de reproduzir sequências musicais e compor sua própria canção por meio das programações do aplicativo.

Figura 8 - Jogo interativo da canção Solstice

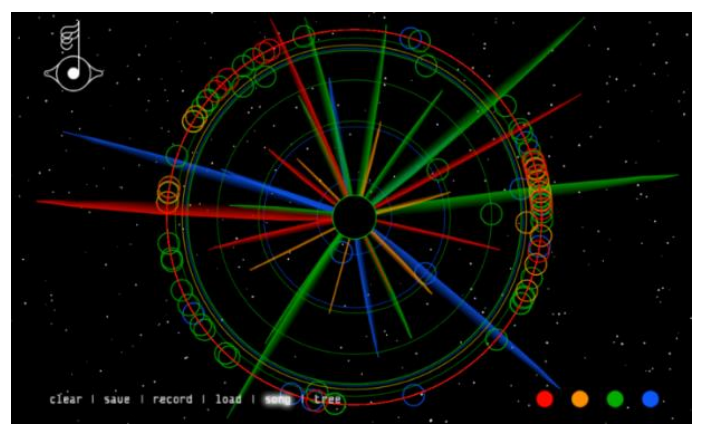

Fonte: Álbum-aplicativo Biophilia (2011)

Por fim, na canção Solstice, Björk celebra a luz das mudanças das estações da natureza manifestadas pela inclinação da órbita da Terra em torno do Sol. Está relacionada ao sistema solar, no qual seu jogo interativo foi inspirado. No espaço, há um Sol centralizado, do qual o usuário arrasta raios de cores diferenciadas e em fases variadas. Enquanto sonoridades da canção são executadas, há a dinâmica interativa com interferências diversas nas reproduções e 
alterações sonoras e visuais. Em torno do Sol, o usuário arrasta os raios e forma círculos que giram como se representassem os planetas da galáxia em movimento ao redor da estrela.

A partir de um Sol localizado no centro da tela, o usuário desenha raios e planetas que giram em sua órbita. Os raios desenhados funcionam como cordas de violão, que são percutidas pelos planetas: quando um planeta toca um raio, uma nota musical é reproduzida. A frequência dessa nota musical é determinada pelo comprimento do raio desenhado (quanto mais longo o raio, mais grave o som). É possível salvar a composição criada e carregá-la posteriormente. (OMINE; HANNS, 2013, p. 5).

Enquanto há o andamento circular do jogo interativo, quando os círculos pequenos alinhados à órbita ultrapassam uma linha de um raio, é emitido um som por meio dos samples de uma harpa, que reproduz dedilhados em órbita das programações do aplicativo. A órbita incorpora a ideia central da inspiração da canção e tem sua relação com o pêndulo e a gravidade do espaço. Quando o usuário altera a inclinação da tela do dispositivo móvel, a imagem muda e a órbita se transforma em uma espécie de árvore iluminada.

\section{CONSIDERAÇÕES FINAIS}

A música como produto comunicacional de consumo mercadológico e midiático, se transformou e evoluiu ao longo dos anos, aliada às constantes inovações tecnológicas e audiovisuais de cada época. Sua produção popular, alternativa e experimental, seja nas esferas underground ou mainstream, se ajusta às necessidades urbanas, mercadológicas, tecnológicas e humanas em constante transformação. Por meio da comunicação entre seus elementos, houve mesclas híbridas inovadoras em seus processos de produção e reprodução sonora, causados pela tecnologia e suas alterações midiáticas.

A distribuição e reprodução do conteúdo foi facilitada pela tecnologia. Com o desenvolvimento dos aplicativos para dispositivos móveis, houve uma significativa transformação midiática na indústria fonográfica graças à criação do álbum-aplicativo, que se torna o novo suporte da indústria musical.

A evolução da tecnologia propiciou inovações na indústria cultural como um todo. Herchmann (2010) e Burkholder, Grout e Palisca (2014) narram a evolução histórica da indústria musical por meio de obras, estilos, gêneros e ideias que influenciaram de modo significativo as mudanças do mercado musical no mundo. Enfatizam a recepção da música e sua influência contínua no contexto histórico e social. Relacionam-se aqui alguns dos tópicos abordados pelos autores com a transição midiática da indústria fonográfica, no caso do álbum-

Comun. \& Inf., Goiânia, GO, v. 20, n. 2, p. 113-131, jul./jun. 2017 
aplicativo, assim como com os novos modelos de negócios que surgem neste início de século XXI e que tendem a se desenvolver nos próximos anos, ganhando cada vez mais força no mercado.

O design de produtos midiáticos inovadores nos meios de comunicação da indústria cultural, graças a seus agentes, artistas e produtores segmentados, cresceu significativamente de modo a gerar criatividade artística, interação midiática, produção estética de qualidade, economia e lucro do setor, em um movimento constante e crescente na produção da indústria cultural, em seus variados setores.

Como resultado, na Tabela 1 são detalhadas algumas características que fomentaram a transição midiática da indústria cultural relacionadas à evolução tecnológica. Essas inovações de linguagem foram observadas e proporcionadas com a criação do álbum-aplicativo e podem ser empregadas pela indústria fonográfica de modo que haja, por meio dessa inovação, a evolução segmentada de setores diversos.

Tabela 1 - Algumas características da transição midiática na indústria fonográfica

\begin{tabular}{|c|l|}
\hline 1 & $\begin{array}{l}\text { Hibridismos, mesclas e sincretismos proporcionados pela glocalização, ao unir o global e o local e } \\
\text { fomentar inovaçoses na indústria. }\end{array}$ \\
\hline 2 & $\begin{array}{l}\text { O desenvolvimento da era digital e a evolução do comércio dos produtos digitais, que ganha cada vez } \\
\text { mais força. }\end{array}$ \\
\hline 3 & $\begin{array}{l}\text { Crescente evolução e inovação em qualidade, suporte, performance, durabilidade dos equipamentos } \\
\text { digitais, o seu barateamento e uso funcional. }\end{array}$ \\
\hline 4 & $\begin{array}{l}\text { Diversificação de plataformas, sistemas operacionais, dispositivos móveis, mídias portáteis, } \\
\text { comunicação midiática, design arrojado e semiótica aplicada aos produtos hipermidiáticos e } \\
\text { multidimensionais. }\end{array}$ \\
\hline 5 & $\begin{array}{l}\text { Acesso democrático à tecnologia da informação, à realidade virtual e à conectividade generalizada na } \\
\text { rede mundial de computadores. }\end{array}$ \\
\hline 6 & $\begin{array}{l}\text { Facilidade no manuseio intuitivo dos equipamentos, envolvimento emocional, compreensão de seus } \\
\text { controles por meio de experiências estéticas, autonomia criativa e emancipação do usuário. }\end{array}$ \\
\hline 7 & $\begin{array}{l}\text { Interação entre produtores, artistas e público por meio da internet e das redes sociais, característica da } \\
\text { cibercultura e do ciberespaço no compartilhamento e imersão do conteúdo. }\end{array}$ \\
\hline 8 & $\begin{array}{l}\text { O advento do Creative Commons, do Crowndfunding e do Streaming, com uma nova visão dos direitos } \\
\text { autorais, formas inovadoras de produção de conteúdo, integração e interatividade, respectivamente. }\end{array}$ \\
\hline 9 & $\begin{array}{l}\text { O desenvolvimento de aplicativos dos mais variados formatos e funções para a facilidade da produção, } \\
\text { com programações, controles e ferramentas de interação e integrações de linguagens proporcionados } \\
\text { pela tecnologia MIDI e a gamificação. }\end{array}$ \\
\hline 10 & $\begin{array}{l}\text { Utilização de diferentes tecnologias desenvolvidas pelos inúmeros softwares e hardwares disponíveis } \\
\text { no mercado, com variados recursos, como os plug-ins de efeitos, equalização, compressão, mixagem, } \\
\text { masterização etc. }\end{array}$ \\
\hline
\end{tabular}

Fonte: Autoria própria

Biophilia é um app para dispositivos móveis com tecnologia Android e iOS para iPhone, iPod, iPad, tablets e smartphones. O usuário tem a possibilidade não só de usufruir das canções, mas também de interagir por meio de hibridismos tecnológicos e criar uma nova

Comun. \& Inf., Goiânia, GO, v. 20, n. 2, p. 113-131, jul./jun. 2017 
canção utilizando jogos, aplicativos e samples disponíveis, tornando-se um coprodutor da obra, além de possuir um álbum-aplicativo com inúmeras aplicações de consumo, criatividade, interação e entretenimento. Para Rossetti (2013), a inovação quando ocorre no objeto, como no caso do álbum-aplicativo, é uma inovação total e uma renovação parcial: total porque o álbum-aplicativo é um produto inédito que não existia anteriormente, e parcial porque o suporte midiático musical obteve uma renovação significativa em sua linguagem. Para a autora:

Quando a inovação está no objeto, o novo pode se referir à totalidade do objeto ou apenas a uma parte do objeto. Quando a inovação é total (diz respeito à totalidade do objeto) tem-se o absolutamente novo, a novidade, aquilo que é inédito e original. A inovação parcial ocorre apenas em parte do objeto e, então, falamos em renovação, incremento, modificação, aperfeiçoamento, em que apenas um detalhe é novo. A inovação total é mais rara e se aproxima das ideias de criação e invenção. Já a inovação parcial é a mais recorrente. No campo da Comunicação, o objeto novo ou inovado pode ser um produto comunicacional, uma teoria da comunicação ou uma linguagem (ROSSETTI, 2013, p. 65).

Essa nova tecnologia entra de forma orgânica no sistema capitalista como um novo suporte de comercialização, colocando o consumidor não mais como indivíduo passivo, mas como ativo quanto à sua interação e integração com o produto. Nele, passa a criar, participar e consumir não mais da forma tradicional como as outras mídias possibilitavam, mas sim de forma inovadora. Esse suporte passa então a abrir as possibilidades de alianças de linguagens e experimentos com integrações entre artista, produto, obra e público. O usuário se torna emancipado por meio da experiência estética inovadora proporcionada pelo álbum-aplicativo e seus modos de interação midiática. Na pós-modernidade, esse consumidor/criador "não se trata de um consumidor qualquer, mas de um consumidor considerado soberano em suas escolhas, em um mercado também considerado livre" (MATTELART; MATTELART, 2012, p. 154), ainda a ser explorado na sociedade glocalizada (TRIVINHO, 2014), com infinitas formas de identidades criativas.

Os “engenheiros de mundos" (LÉVY, 1999), ao criarem o álbum-aplicativo, desenvolveram um produto da "ciberarte". Realizaram uma simulação do mundo real e virtual. Criaram alternativas de composição criativa e de produção cultural em um produto hipermidiático inacabado, com amplas possibilidades multiformes de explorações e construções múltiplas nos gêneros ciberculturais por parte de seus usuários e idealizadores. 
Fomentaram uma nova dinâmica à produção musical com fusão de linguagens diversas em constante evolução.

Em “álbuns-aplicativos" como Biophilia (2011), os "engenheiros de mundos" celebram uma renovação na forma de se obter um produto hipermidiático mais acessível, tecnológico, o qual propicia uma maior interação e comunicação por parte do artista com seu público graças ao novo suporte midiático e à tecnologia digital. O usuário imersivo, cocriador, característica da cibercultura, é o centro das atenções e se configura como uma nova tendência em aplicações híbridas culturais da "era digital", que se propaga com novas possibilidades de comunicação, cooperação, interatividade e performance entre os atores.

A gamificação, ou jogo comunicativo entre linguagens criativas, existente nos dispositivos móveis é um dos fatores principais desse novo fenômeno, ou seja, o ato de jogar, criar e recriar, em constante cooperação e comunicação, traduz e resulta nos processos inovadores que emergem de múltiplas formas e interesses híbridos, tecnológicos e midiáticos.

Biophilia também se caracteriza por oferecer possibilidades de novas gerações artísticas/culturais, de novas produções, de uniões/fusões por parte de artistas, produtores, gravadoras, selos e empresas de diversos setores. O álbum-aplicativo prospecta novos negócios multimilionários em todo o mundo, junto à cultura da convergência (JENKINS, 2009), integrações tecnológicas e às características das novas mídias (MANOVICH, 2001) da cibercultura contemporânea (LÉVY, 1999; LEMOS, 2003) na "era digital", com foco no homem imersivo da híbrida pós-modernidade (HALL, 2015) ao propiciar outras experiências inovadoras.

\section{REFERÊNCIAS}

BURKE, Peter. Hibridismo cultural. São Leopoldo: Unisinos, 2003.

BURKHOLDER, J. Peter; GROUT, Donald Jay; PALISCA, Claude V. A history of western music. New York: W.W. Norton \& Company, 2014.

CANCLINI, Néstor García. Culturas híbridas: estratégias para entrar e sair da modernidade. Trad. Heloísa Pezza Cintrão e Ana Regina Lessa. 4. ed. 6. reimp. São Paulo: EDUSP, 2013.

DUARTE Jorge; BARROS Antônio. Métodos e técnicas de pesquisa em comunicação. 2 ed. -8 reimpr. - São Paulo: Atlas, 2015.

GARCIA, Jaimeson Machado; KESSLER, Janea. As conexões entre a identidade visual do projeto musical Biophilia com o contexto pós-moderno. V SIPECOM - Seminário

Internacional de Pesquisa em Comunicação, UFSM, p. 1-15, 15 a 17 de outubro de 2013.

Comun. \& Inf., Goiânia, GO, v. 20, n. 2, p. 113-131, jul./jun. 2017 
HALL, Stuart. A identidade cultural na pós-modernidade. Trad. Tomaz Tadeu da Silva e Guacira Lopes Louro. 12. ed. Rio de Janeiro: Lamparina, 2015.

HERSCHMANN, Micael. Indústria da música em transição. São Paulo: Estação das Letras e Cores, 2010.

JENKINS, Henry. Cultura da convergência. Trad. Susana L. de Alexandria. 2. ed. São Paulo: Aleph, 2009.

LEMOS, André. Cibercultura: alguns pontos para compreender a nossa época. In: LEMOS, André; CUNHA, Paulo (Org.). Olhares sobre a Cibercultura. Porto Alegre: Sulina, 2003, p. $11-23$.

LEMES, D; TOMASELLI, F; CAMAROTTI, S. A economia digital e o mercado de jogos para dispositivos móveis. XI SBGames, Brasília, nov. 2012.

LÉVY, Pierre. Cibercultura. Trad. Carlos Irineu da Costa. São Paulo: Ed. 34, 1999.

MANOVICH, Lev. The Language of New Media. London: The MIT Press, 2001.

MATTELART, Armand; MATTELART Michèle. História das teorias da comunicação. Trad. Luiz Paulo Rouanet. 15. ed. São Paulo: Loyola, 2012.

OMINE, E.; HANNS, D. K. Design computacional em aplicativos para tablets. In: ENCONTRO INTERNACIONAL DE ARTE E TECNOLOGIA, 12. Anais, Brasília, p. 1-10, 2013.

ROSSETTI, Regina. Categorias de inovação para os estudos em Comunicação. Revista Comunicação \& Inovação, São Caetano do Sul, v. 14, n. 27, p. 63-72, jul.- dez. 2013.

SHANKARI, K; PARK, J. GADBIL, T; KATZ, R; CULLER, D. Information Display for Societal Problems: Data, Game, or Choice? Electrical Engineering and Computer Sciences, University of California at Berkeley, p. 1-8, 2015.

TRIVINHO, Eugênio. A civilização glocal: repercussões social-históricas de uma invenção tecnocultural fundamental do capitalismo tardio. In: (Org.). A condição glocal: configurações tecnoculturais, sociopolíticas e econômico-financeiras na civilização mediática avançada. São Paulo: Annablume; FAPESP, 2014.

VARGAS, Herom; GOULART, Elias. Tecnologia, comunicação e produção cultural: o exemplo da música popular. In: CAPRINO, Mônica Pegurer (Org.). Comunicação e inovação: reflexões contemporâneas. São Paulo: Paulus, 2008, p. 161-199. 